University of Nebraska - Lincoln

DigitalCommons@University of Nebraska - Lincoln

2013

\title{
Meeting the Leadership Challenge of Employee Well-Being Through Relationship PsyCap and Health PsyCap
}

Fred Luthans

University of Nebraska-Lincoln, fluthans1@unl.edu

Carolyn M. Youssef

Bellevue University, carolyn.youssef@bellevue.edu

David S. Sweetman

University of Michigan - Ann Arbor, dsweetma@umich.edu

Peter D. Harms

University of Nebraska - Lincoln, pharms@gmail.com

Follow this and additional works at: https://digitalcommons.unl.edu/managementfacpub

Luthans, Fred; Youssef, Carolyn M.; Sweetman, David S.; and Harms, Peter D., "Meeting the Leadership Challenge of Employee Well-Being Through Relationship PsyCap and Health PsyCap" (2013).

Management Department Faculty Publications. 103.

https://digitalcommons.unl.edu/managementfacpub/103

This Article is brought to you for free and open access by the Management Department at DigitalCommons@University of Nebraska - Lincoln. It has been accepted for inclusion in Management Department Faculty Publications by an authorized administrator of DigitalCommons@University of Nebraska - Lincoln. 


\title{
Meeting the Leadership Challenge of Employee Well-Being Through Relationship PsyCap and Health PsyCap
}

\author{
Fred Luthans,' Carolyn M.Youssef, ${ }^{2}$ David S. Sweetman, ${ }^{3}$ and Peter D. Harms 1 \\ I. University of Nebraska-Lincoln, Lincoln, NE \\ 2. Bellevue University, Bellevue, NE \\ 3. University of Michigan, Ann Arbor, MI \\ Corresponding author — Fred Luthans, Department of Management, University of Nebraska-Lincoln, \\ Lincoln, NE 68588-049I; email fluthans1@unl.edu
}

\begin{abstract}
Increasing recognition is being given to the role that employee overall well-being plays in desired outcomes of today's organizations. To help organizational leaders searching for understanding and answers, we propose that the positive core construct of psychological capital (or simply PsyCap), consisting of the positive psychological resources of hope, efficacy, resiliency, and optimism can be extended into the well-being domain. Although PsyCap has been clearly demonstrated to be related to employee attitudes, behaviors, and performance, linking it with other life domains relevant to overall well-being has yet to be tested. After first building a comprehensive conceptual foundation for extending PsyCap into the well-being domain, we empirically found that a cross section of employees' $(N=523)$ "Relationship PsyCap" and "Health PsyCap" were related to both their respective satisfaction appraisals and desired objective outcomes. In addition, these two extended life satisfactions, along with the already well-established work satisfaction, combined to relate to the appraisal of the study participants' overall well-being. This well-being was in turn found to be related to their overall level of PsyCap. These findings have implications for helping leaders meet the challenges they face in both understanding and helping develop the overall well-being of their employees.
\end{abstract}

Keywords: leadership and well-being, psychological well-being, psychological capital, health psychological capital, relationship psychological capital

The leadership field has been giving increasing attention to the impact that leadership styles and behaviors have on employee health and well-being (for a relevant meta-analysis, see Kuoppala, Lamminpaa, Liira, \& Vainio, 2008). In addition, the core construct of psychological capital (PsyCap) has been applied to both well-being (Avey, Luthans, Smith, \& Palmer, 2010) and leadership (e.g., see Luthans \& Avolio, 2003; Youssef \& Luthans, 2012). However, extending PsyCap into the life domains of relationships and health to help today's organizational leaders meet the challenges of employee well-being has not yet been attempted. Thus, the purpose of this study is to extend the now widely recognized core construct of "Psychological Capital" or simply PsyCap (e.g., see Luthans, Avolio, Avey, \& Norman, 2007; Luthans \& Youssef, 2004; Luthans, Youssef, \& Avolio, 2007) in the assessment of employees' relationships, and health in order to help leaders better understand and help develop their employees' overall wellbeing. Specifically, we extend the PsyCap construct and measure to assess psychological positivity beyond work into other important life domains, which we term for the first time Relationship PsyCap and Health PsyCap.

Our research question is whether these two life domains of Relationship PsyCap and Health PsyCap extend beyond Work PsyCap to better understand and relate to employee well-being. There is already considerable theory and research regarding PsyCap in relation to work, but there is a need to investigate whether PsyCap relates to both relationship and health satisfaction appraisals and other reported objective outcomes (i.e., time spent with family and friends for relationships, attaining optimum body mass index (BMI) and cholesterol levels for health). The intent is not to proliferate or dilute the now-recognized positive core construct of PsyCap but instead to extend it into relationships and health well-being and contribute to its external validity. Specifically, we test whether employees' relationship and health satisfaction, combined with their work satisfaction, relate to their appraisal of overall well-being, and whether this in turn relates to their overall level of PsyCap. 


\section{Theoretical Foundation}

As indicated, the major purpose of this article is to contribute to leaders' better understanding of the role PsyCap may play in their employees' well-being. Thus, we provide a relatively more detailed theoretical foundation for the background and derivation of hypotheses than is typically found for an empirical study. To begin this understanding, we should recognize that there are two traditionally recognized theoretical views in relation to one's well-being. The first represents the topdown, or dispositional, approach, in which personality differences are viewed as antecedents to well-being. The second is a bottom-up approach that emphasizes the situational determinants of well-being and overall life satisfaction. Empirical findings to date support an integration of both perspectives (for comprehensive reviews, empirical support, and meta-analytic findings, see Brief, Butcher, George, \& Link, 1993; Diener, Suh, Lucas, \& Smith, 1999; Heller, Watson, \& Ilies, 2004). Collectively, these findings provide strong evidence that the impact of individual differences and contextual factors is indirect and integrative and often influenced by cognitive appraisals of objective life events. This is also consistent with the recent views from positive psychology that well-being is determined through a combination of dispositional, situational, and intentional factors (Lyubomirsky, 2007).

The positivity levels of one's predispositions, appraisals, memories, goals, and motivations are instrumental in magnifying the impact of positive events. Such positivity also buffers the effects of negative events. In other words, positivity becomes more relevant to domain satisfaction and overall well-being than objective life events and circumstances. More specifically, objective life events and circumstances have been estimated from the positive psychology research literature to account for only about $10 \%$ of happiness (Lyubomirsky, 2007). On the other hand, positive predispositions, or what has been referred to as the set point, have been shown to account for about $50 \%$ of well-being (Lykken \& Tellegen, 1996; Lyubomirsky, 2007). This leaves as much as $40 \%$ of well-being open to development and growth through intentional positivityenhancing activities (Lyubomirsky, 2007; Lyubomirsky, Sheldon, \& Schkade, 2005).

Intentional well-being has been empirically supported through meta-analysis as a cause of success in various domains of life (e.g., work, relationships, health) rather than predetermined luck or the result of good fortune (Lyubomirsky, King, \& Diener, 2005). Thus, we hypothesized intentional, developmental positivity, operationalized and measured by statelike PsyCap (rather than trait-like personality dispositions), as being both an antecedent to domain-specific satisfaction and, in turn, overall well-being and, in ad- dition, that such positivity (PsyCap) is an outcome of overall well-being.

In the theoretical foundation for this study, although we acknowledge the dispositional, top-down perspective and the potential impact of a "happiness baseline" or "set point" (Lykken \& Tellegen, 1996; Lyubomirsky, 2007) on overall well-being, we also emphasize the dynamic nature and developmental potential that positive psychological resources such as PsyCap (covered next) has been found to have on well-being over time (e.g., Avey et al., 2010). Moreover, although we recognize the situational, bottom-up perspective and the potential impact of objective life events, we developed and tested an expanded conceptualization in which positive appraisals of those events lead to higher levels of well-being at, and beyond, the well-documented work domain to also include relationship and health domains.

Importantly, positive psychology recognizes that life satisfaction may be greater than the aggregate of the specific life domains that make it up (Diener, Napa-Scollon, Oishi, Dzokoto, \& Suh, 2000). Thus, we hypothesized that although component life domains such as work, relationships, and health may be related to one's overall well-being, there is also a key role one's level of positivity (i.e., PsyCap) may play in facilitating favorable appraisals of these domains. For example, Diener et al. (2000) have demonstrated that people's well-being is not just the sum of their domain-specific (i.e., work, health, and relationships) satisfaction appraisals. They also emphasize the role that positivity (i.e., PsyCap) seems to play in the overall appraisal.

\section{Psychological Capital Representing Positivity of Employees in the Workplace}

Although the value of positivity has been recognized since the Greek philosophers, it has recently undergone a revival of interest, focus, and research attention, both in clinical psychology (the positive psychology movement; Lopez \& Snyder, 2009; Seligman \& Csikszentmihalyi, 2000) and in organizational behavior (Cameron, Dutton, \& Quinn, 2003; Cameron \& Spritzer, 2012; Luthans, 2002, Luthans \& Avolio, 2009). Positivity has been conceptualized and measured in terms of positive traits such as stable character strengths and virtues (C. Peterson \& Seligman, 2004) as well as positive states and state-like psychological resources that can change in response to life events and intentional human resource development interventions (see Luthans \& Youssef, 2007, for an indepth discussion of the trait-state continuum). Moreover, positive constructs have been shown to be both global in nature and situational in their manifestation. For example, optimism has been shown to constitute both generalized positive expectancies (Carver \& Scheier, 2002) and an event-based positive explanatory style (Seligman, 
1998). Self-efficacy has also been conceptualized and validly measured both as generalized (Schwarzer \& Jerusalem, 1995) and as domain specific (Bandura, 1997).

In addition to being both a trait and a state, and also general and specific, positivity also encompasses a wide range of constructs that vary in their cognitive and affective content. For example, Fredrickson's (2001) broaden-and-build model of positive emotions depicts the impact of a positive affective state in terms of broadened thought-action repertoires, as well as increased or replenished inventories of physical, mental, social, and psychological resources. On the cognitive side, PsyCap has been defined as

\begin{abstract}
an individual's positive psychological state of development that is characterized by: (1) having confidence (self-efficacy) to take on and put in the necessary effort to succeed at challenging tasks; (2) making a positive attribution (optimism) about succeeding now and in the future; (3) persevering toward goals and, when necessary, redirecting paths to goals (hope) in order to succeed; and (4) when beset by problems and adversity, sustaining and bouncing back and even beyond (resiliency) to attain success. (Luthans, Youssef, et al., 2007, p. 3)
\end{abstract}

Empirically demonstrated to be a latent multidimensional core construct (Luthans, Avolio, et al., 2007), PsyCap is explained in terms of being an underlying cognitive agentic component shared among its four constituent capacities (hope, efficacy, resilience and optimism) representing "one's positive appraisal of circumstances and probability for success based on motivated effort and perseverance" (p. 550).

In the workplace, PsyCap has been demonstrated through control group, pretest-posttest experimental designs to be open to development and change through short training interventions (Luthans, Avey, Avolio, \& Peterson, 2010; Luthans, Avey, \& Patera, 2008). These findings have practical implications for human resource development. They indicate PsyCap can be developed in short training programs (see Luthans, Youssef, et al., 2007, Chapter 8, and Luthans, 2012, for specific guidelines). However, this research also indicated that PsyCap still had a relatively balanced level of stability and malleability (e.g., compared with emotional states or the more fixed personality traits such as conscientiousness; Luthans, Avolio, et al., 2007; also for longitudinal research support, see S. J. Peterson, Luthans, Avolio, Walumbwa, \& Zhang, 2011). In other words, PsyCap is best described empirically as falling into the middle ground of the trait-state continuum (see Luthans \& Youssef, 2007; Luthans, Youssef, et al., 2007).

However, although primarily cognitive in nature, PsyCap is not considered to be absent of a positive emotional component (e.g., see Bandura, 2008; C. R. Snyder, Ilardi, Michael, \& Cheavens, 2000). Its four constituent facets have been shown in the positive psychology literature to relate to a wide range of outcomes in various life domains (for summaries, see Lopez \& Snyder, 2009). Specifically, PsyCap is intended to be relevant to both global and domain-specific life appraisals (Luthans, Youssef, et al., 2007). Thus, to help leaders better understand the nature of employee wellbeing, as well as to provide the conceptual framework for this study, we used PsyCap as a balanced operationalization of positivity, and we expanded and tested its boundaries by going beyond the occupational or work domain and into the other pertinent life domains of relationships and health.

\section{Going Beyond Work PsyCap: Health PsyCap and Relationship PsyCap}

PsyCap, as well as its constituent capacities of hope, efficacy, resiliency, and optimism have been shown in previous research to be related to employee attitudes, behaviors, and performance in the workplace (e.g., for a recent metaanalysis, see Avey, Reichard, Luthans, \& Mhatre, 2011; and also see Luthans, Avolio, et al., 2007; S. J. Peterson \& Byron, 2008; S. J. Peterson et al., 2011; Stajkovic \& Luthans, 1998; Youssef \& Luthans, 2007). Since PsyCap within the occupational domain has this clearly established relationship with both objective outcomes and work satisfaction, the present study focused whether positivity, operationalized as domain-specific PsyCap, correlates with desired objective outcomes in and satisfaction appraisals of the other two most widely recognized important life domains of health and relationships.

Although positivity in general has been supported as an antecedent to good health and social relationships (e.g., see Lyubomirsky, King, et al., 2005, Lyubomirsky, Sheldon, et al., 2005), we hypothesized that the core construct of PsyCap is instrumental for not only the realization of employees' work PsyCap impact on objective outcomes (e.g., performance, see Luthans, Avolio et al., 2007; S. J. Peterson et al., 2011) and satisfaction (see Avey, Reichard, et al., 2011; Luthans, Avolio et al., 2007) but also for positive objective outcomes and positive appraisals of (satisfaction with) their health and relationships.

\section{Impact of Health PsyCap}

Adapted from previous PsyCap conceptualizations and research, Health PsyCap is defined as drawing from one's psychological resources of hope, efficacy, resiliency and optimism in making positive appraisals of health-related circumstances and probability for health-related success based on motivated effort and perseverance. We propose that Health PsyCap is related to objective health outcomes such as BMI and cholesterol level as well as subjective satisfactory appraisals. 
In the psychology literature over the years, positive relationships between PsyCap's constituent capacities and health have been empirically supported. For example, meta-analytic findings found efficacy as a consistent predictor of health-related outcomes (Holden, 1991). Hope and optimism have also been shown to predict health (Scioli et al., 1997). Although more related to positive reactions to adversity, resiliency is also related to health in terms of effective treatment, prevention, and coping (e.g., Holaday \& McPhearson, 1997; SandauBeckler, Devall, \& de la Rosa, 2002).

Besides these empirical findings on the individual facets, there is related theoretical support for the contribution of overall PsyCap to health outcomes that may go beyond the combined impact of PsyCap's constituent capacities. Specifically, PsyCap's definition and empirical support as a core construct (Luthans, Avolio, et al., 2007) indicates underlying cognitive agentic mechanisms that may trigger the choice of challenging goals with alternative pathways to overcome encountered problems (hope), motivate effort and perseverance (efficacy), generate positive outcome expectancies and explanatory styles (optimism), and facilitate bouncing back from adversity (resiliency). Acting in concert and specifically targeting the domain of health, these mechanisms allow for self-directed health management beyond any one of the psychological resources. This is not to deny the impact of genetics and environmental influences on health but rather to emphasize the significant impact of intentionality (i.e., PsyCap) toward one's health and the wide resultant scope for development in health outcomes and appraisals despite the largely uncontrollable set factors. For example, in the medical and pharmaceutical fields, the recent rise in the use of complementary and alternative medicine, especially among adults and children of parents with health care cost concerns (Barnes, Bloom, \& Nahin, 2009), may be a phenomenon that is reflective of PsyCap's underlying cognitive agentic component. One's Health PsyCap may also contribute to intentional strong motivation and desire for better health and relief from illness, even when access to conventional, tried-and-true health care is perceived to be limited or denied.

The integration represented by Health PsyCap may also protect individuals from pitfalls of extreme, Pollyannaish positivity. For example, overconfidence or unrealistic optimism can be conducive to risky behaviors (e.g., ignore sleep or nutrition, skip checkups, do no exercise) that can be detrimental to one's health (Davidson $\&$ Prkachin, 1997). However, the other components of PsyCap may counteract the dysfunction of such overoptimism. Specifically, the pathway coming from the hope component of Health PsyCap may help ground positive expectancies of future health within the realities of the steps and goals to be pursued in the hope process (e.g., regular exercise, optimal weight through eating right, seeking regular medical attention), and the obsta- cles to be conquered (e.g., genetics, unhealthy habits). The same can be said for all four of the components of PsyCap counterbalancing potential dysfunctions of one another. This leads to the first study hypothesis:

Hypothesis 1a: Health-focused PsyCap relates to objective health outcomes, where higher Health PsyCap is related to more favorable objective outcomes for BMI and cholesterol levels.

Conceptual and empirical evidence also suggests that Health PsyCap may be related to subjective appraisals of satisfaction with one's health. For example, PsyCap involves appraising one's circumstances in a positive manner (Luthans, Avolio, et al., 2007; Luthans, Youssef, et al., 2007). This could mean that two individuals may have objectively comparable health, but the one with higher Health PsyCap may experience higher health satisfaction because of a more favorable, positive appraisal. This does not mean that positivity is automatically conducive to unrealistically favorable appraisals of one's health. Instead, positivity may simply help overcome the predominant negative bias (Baumeister, Bratslavsky, Finkenauer, \& Vohs, 2001). Such negativity may unnecessarily magnify the impact of health setbacks (Diener \& Biswas-Diener, 2008).

Beside combating the tendency to be negative, an agentic positive approach represented by Health PsyCap may also help trigger effective health-related planning and goal setting. Such forward-oriented activities can have a positive impact, both in terms of objective health outcomes (Hypothesis 1a) and in terms of personally meaningful health goals. A desirable side effect is the resulting motivation, commitment, and satisfaction with the process of achieving health goals. For example, those who make their goal weight or quit smoking tend to be very satisfied. As discussed earlier, since our focus is on well-being, which has been shown to be more strongly related to cognitive appraisals than to objective events, the contribution of Health PsyCap to health satisfaction seems particularly relevant, hence the following study hypothesis:

Hypothesis 1b: Health-focused PsyCap is related to health satisfaction, where higher Health PsyCap is related to higher subjective appraisals of satisfaction with health.

\section{Impact of Relationship PsyCap}

Dutton and Ragins (2007, pp. 5-6) note that everyone recognizes that "relationships are central to life both within and outside the workplace, and that the need for authentic relationships is not left at the workplace door." Similar to the life domain of Health PsyCap, we define Relationship PsyCap as drawing from one's psychological resources of hope, efficacy, resiliency and optimism in making positive ap- 
praisals of relationships and probability for relationship success based on motivated effort and perseverance. Previous research suggests that PsyCap, specifically with regard to one's relationships, may be related to both objective measures, such as spending time with family and friends, and the subjective appraisal of the satisfaction with one's relationships. In addition to the considerable research showing the relationships between positivity and both effective social relationships and teamwork (e.g., Dutton \& Ragins, 2007; Losada \& Heaphy, 2004; Lyubomirsky, Sheldon, et al., 2005), positivity has also been found to be conducive to the broadening and building of social resources (Fredrickson, 2009). Moreover, PsyCap's agency and intentionality in consciously choosing one's relationships can help enhance positive emotional contagion effects (Barsade, 2002; Segrin, 2004).

Research over the years has indicated that negative interactions tend to dominate relationship appraisals for neutral relationships, or even for those that are slightly, but not highly, positive (e.g., studies have shown that marriages with 6 positive to 1 negative ratio are more successful than those weighted more heavily toward the negative; Gottman, 1994). PsyCap's agentic approach is of particular relevance in triggering the intentional activities necessary for generating a higher ratio of positive to negative interactions in satisfying relationships with others (Fredrickson, 2009). For example, new hope pathways can be generated (e.g., finding new ways to spend more time with family and friends). The same is true for generating optimistic expectancies. Optimism can be created toward future interactions. An optimistic explanatory style can be used in interpreting others' attitudes and behaviors. Optimistic attributions can increase the frequency and intensity of positive interactions. Relationship PsyCap may also buffer the effects of negative interactions through renewed efficacy or resiliently bouncing back, which may result in more successful relationships and higher levels of relationship satisfaction.

Based on the above, although one's relationships may vary in positivity, intensity, controllability, and potential impact, the evidence seems to indicate that agentic, intentional Relationship PsyCap may play an important role in enhancing positive relationships, boosting neutral relationships, creating new relationships, mending strained relationships, and viewing negative relationships in a more favorable light. The result can be manifested in terms of increased breadth and depth of one's relationships, with more favorable appraisals of relationships, as well as objective outcomes of relationships such as spending more time with family and friends. Thus, the following study hypotheses are derived:

Hypothesis 2a: Relationship-focused PsyCap is correlated with relationship satisfaction, where higher Relationship PsyCap is related to higher subjective appraisals of satisfaction with relationships.
Hypothesis 2b: Relationship-focused PsyCap is correlated with relationship objective outcomes, where higher Relationship PsyCap is related to the favorable objective outcome of spending more time with family and friends.

\section{Domain-Specific Satisfaction With Work, Relationships, and Health and Overall Well-Being}

As discussed earlier, individuals' subjective, domain-specific satisfaction appraisals have been found to be more strongly related to their overall well-being than have objective outcomes (Diener \& Biswas-Diener, 2008; Emmons \& Diener, 1985). Thus, there is evidence to suggest that satisfaction with work, health, and relationships may be related to the appraisal of one's overall well-being.

\section{Work Satisfaction and Well-Being}

Even though the purpose of this study was to extend PsyCap from work to the other important life domains of relationships and health, for assessing overall wellbeing, work remains a significant part of almost all adults' daily life, and job satisfaction has been shown to be related to life satisfaction (Judge \& Watanabe, 1993). Work can be a source of experienced meaningfulness, perceived competence, autonomy, goal progress, and social support, all of which can be conducive to wellbeing beyond the workplace (Ryan \& Deci, 2001). On the other hand, work can also be a source of stress and burnout that can also carry over beyond the workplace. Indeed, both positive and negative spillover effects have been found between one's job satisfaction and other life domains (e.g., Judge \& Ilies, 2004). Moreover, work-related negative events such as unemployment or working in a demeaning job have been shown to have a long term impact on well-being through altering one's happiness set point (Biswas-Diener \& Diener, 2001; Lucas, Clark, Georgellis, \& Diener, 2004). Thus, although work's extrinsic motivation as a means to the accumulation of material wealth may only modestly influence well-being (Biswas-Diener \& Diener, 2001; Biswas-Diener, Vitterso, \& Diener, 2005), and may exhibit diminishing marginal utility (Diener, $\mathrm{Ng}$, \& Tov, 2009), job satisfaction may still be instrumental for global appraisals of life satisfaction and well-being.

\section{Relationships Satisfaction and Well-Being}

Besides work satisfaction, satisfaction with relationships has also been shown to be one of the strongest predictors of well-being. Specifically, satisfying relationships are deemed essential for fulfilling basic human needs for affiliation, secure attachment, and intimacy, which in turn are instrumental for well-being (Ryan \& Deci, 
2001). For example, Diener and Seligman (2002) found that happy people consistently report highly positive social relationships. Extreme satisfaction with intimate relationships, even to the extent of idealization of partners and positive illusions about them, have been found optimal for happiness and well-being, since they promote stable, higher quality relationships (Murray, Holmes, \& Griffin, 2003; Oishi, Diener, \& Lucas, 2007). On the other hand, moderate or low relationship satisfaction can prompt the search for alternative partners (e.g., Rusbult, 1980), which may be detrimental for overall well-being. Loss of intimate relationships (e.g., in the form of widowhood) has been shown to negatively alter one's happiness set point in the long run (Lucas, Clark, Georgellis, \& Diener, 2003).

\section{Health Satisfaction and Well-Being}

Besides work and relationship satisfaction, there is evidence suggesting that the third important life domain of health is also related to overall well-being. For example, although the strength of the relationship between objective health outcomes and well-being appear modest, studies have found that positive self-appraisals of satisfaction with health are predictive of well-being (Okun, Stock, Haring, \&Witter, 1984; also see Pfeffer, 2010). There appear to be two major reasons why health satisfaction is related with overall well-being.

First, health is a personal life domain that can influence people's ability to reach their goals. Perceived good health can free additional cognitive, affective and physical resources toward the pursuit of meaningful personal goals and aspirations. On the other hand, poor health can be viewed as a frustration of goal pursuit. Goal pursuit has been shown to be instrumental for well-being, whereas factors that are perceived as hindrances to the goal pursuit process have been related to lower appraisals of well-being (Kim-Prieto, Diener, Tamir, Scollon, \& Diener, 2005). Second, healthy individuals may still pursue health-related goals (e.g., weight maintenance, regular exercise, adequate sleep), but these goals will likely be framed as approach goals (e.g., I want to be healthy 10 years from now). On the other hand, dissatisfaction with one's health may promote avoidance goals (e.g., skipping meals or social gatherings, excluding desired foods from the diet, taking time away from desired activities to exercise). Approach goals have been shown to enhance well-being, whereas avoidance goals have been shown to reduce it (Carver \& Scheier, 1999; Elliot \& Sheldon, 1997; Elliot, Sheldon, \& Church, 1997).

\section{Combined Effect on Well-Being}

We propose that satisfaction with work, relationships, and health can separately and integratively contribute and are significantly related to people's appraisal of their overall well-being. The combined contribution of the three domain-specific satisfactions can be theoretically explained through several cognitive mechanisms. The first proposed mechanism is additive and compensatory in nature, in which the three domain-specific satisfactions act in concert to reach a "tipping point." It has been empirically found that the predominant human bias toward negativity requires a positivity ratio of about 3 to 1 in order to overcome negativity and meet the threshold that distinguishes flourishing from languishing (Fredrickson, 2009; Fredrickson \& Losada, 2005; Losada \& Heaphy, 2004). However, the media regularly publicize statistics showing that negativity is on the rise. For example, the economy is not doing well and unemployment is too high. Divorce rates are too high, and so are crime rates, heart attacks, and especially waist circumferences. This negatively biased exposure makes it more difficult to reach a positivity ratio that can be conducive to a high level of well-being.

Although positivity thresholds within specific domains have been supported, we suggest that to become positive, one needs to capitalize and balance every major domain of life, of which work, health, and relationships are all invaluable. In other words, positivity in some life domains may compensate for negativity in other domains, which on balance may result in a high level of well-being. This is consistent with the empirical findings. Although domain satisfactions may be weakly related to each other, they significantly contribute to overall life satisfaction and well-being (Heller et al., 2004). This suggests that satisfaction with work, relationships, and health may combine to become related to overall of well-being.

The second mechanism can be viewed from a perceptual, interpretive perspective. Beside positive over negative ratios, long-term influences on well-being are also caused by retained memories of events. Such memories have been shown to be both quantitatively and qualitatively different from real-time experiences (Kahneman, 1999; Thomas \& Diener, 1990) and depend on the current state of the individual (Kim-Prieto et al., 2005) that is, one's level of PsyCap (Avey et al., 2010) - and they are especially dependent on current appraisals (i.e., domain satisfaction; Levine, 1997; Levine, Prohaska, Burgess, Rice, \& Laulere, 2001). Positive experiences can facilitate the attention, interpretation, and memory retention processes necessary for a lasting impact on wellbeing (Diener \& Biswas-Diener, 2008; Lyubomirsky, 2001). Satisfaction with one's work, health, and relationships may promote the savoring of the positive experiences in these areas, which in turn may over the long run facilitate the memory processes that mediate the impact of these and other experiences on well-being.

The third mechanism is adaptational in nature. It has been debated, with the exception of major life setbacks that can present severe challenges in the pursuit of important personal goals (e.g., unemployment, widowhood), 
whether human adaptation can return most people to their happiness set point, a process that has been termed the hedonic treadmill (Brickman \& Campbell, 1971; also see Diener, Lucas, \& Scollon, 2006, for a comprehensive review of this issue). However, this set point has also been shown to be a "soft baseline" that gradually shifts over time for about 1 in 4 people, with about 1 in 10 changing by as much as $30 \%$ (Fujita \& Diener, 2005). Additionally, a focus on happiness as a goal has been shown to actually result in a lower appraisal of overall well-being (Schooler, Ariely, \& Loewenstein, 2003). On the other hand, the continuous pursuit of new goals can promote higher well-being (Kim-Prieto et al., 2005). In other words, happiness has been supported more as a process than as a destination (Diener, Oishi, \& Lucas, 2009; Lyubomirsky, King, et al., 2005). This evidence suggests that sustaining satisfaction with multiple life domains may likely be more conducive to the novelty and variety of goals necessary to overcome the hedonic treadmill and to achieve and maintain higher levels of overall wellbeing. Thus, the following hypothesis was tested:

Hypothesis 3: Domain-specific satisfaction (work, relational, and health) together relate to overall well-being, where higher combined domain-specific satisfaction is related to higher appraisals of overall well-being.

\section{Closing the Positivity Loop: Relationship of Overall Well-Being With Overall Positivity (PsyCap)}

As indicated, there is extensive support for the notion that happiness is a process, not a place. As such, pursued as a terminal value, the singular goal of increasing happiness may actually result in lower well-being (Schooler et al., 2003). Yet, as has been demonstrated, well-being can also be sustainably increased through intentional activities and structured interventions (Lyubomirsky, Sheldon, et al., 2005). One way to explain this paradox is that there may be a temporal sequence. We propose the key to this sequence or process starts with high domain-specific PsyCap leading to increased domain satisfaction. This domain satisfaction leads to higher overall well-being, and this higher level of well-being in turn leads to increased overall positivity (PsyCap). In other words, overall well-being is a process that starts and ends with higher levels of positivity.

We suggest that the core construct of PsyCap is a relevant operationalization for this mutually reinforcing path of positivity, particularly because of the developmental nature of PsyCap over time. This is consistent with Kim- Prieto et al.'s (2005) time-sequential model of wellbeing. In this model, well-being systematically unfolds and changes over time through the interplay of memoryshaping cognitive appraisals of and emotional reactions to events (i.e., domain-specific satisfaction). The changes in wellbeing are in turn shaped by goal pursuits, motivational concerns, and explanatory styles (i.e., PsyCap).

Furthermore, positivity can promote the selective retention of positive memories of events. These memories can result in positive appraisals of those events and hence in domain satisfaction. In turn, positive appraisals can have an influence not only on overall well-being but also on realigning future behaviors with past behaviors that are perceived and remembered to have yielded higher satisfaction levels (Oishi, 2002; Wirtz, Kruger, Scollon, \& Diener, 2004). For example, a high-PsyCap individual who chooses to volunteer for a challenging project, and experiences high job satisfaction and overall well-being as a result, may choose to do that again in the future. In other words, domain PsyCap can reinforce a positive cognitive, affective, and behavioral cycle. In turn, that person's overall PsyCap may increase as new and less familiar challenges are pursued, maybe even beyond the immediate job responsibilities (e.g., in case of a promotion), and in other life domains. For example, positive contagion, spillover effects, and crossover effects (Bakker, Westman, \& Van Emmerik, 2009) may influence others through that person's relationships as well. Over time, this person's overall positivity ratio is likely to increase, through positive objective events such as success at work, positive encounters with relationships, and better physical and psychological health. More important, however, positive appraisals of those events in multiple life domains can be integrated into higher overall well-being.

Finally, as indicated, the common core thread running through PsyCap is a cognitive agentic component that motivates effort, perseverance, and a positive outlook throughout the process of pursuing challenging goals one chooses to believe are possible. Happiness has been supported as a causal antecedent to positive perceptions of self-competence (i.e., efficacy), effective coping mechanisms (i.e., resiliency), higher activation levels (i.e., optimism), and superior problem-solving skills (i.e., hope; see Lyubomirsky, Sheldon, et al., 2005). In other words, a person with high overall well-being is likely to build and sustain high overall PsyCap levels. This helps not only in terms of domain-specific cognitive appraisals but also in the form of general, overarching mechanisms for self-evaluation, coping, problem solving, and overall energy levels. Thus, the final study hypothesis is the following:

Hypothesis 4: Overall well-being is positively related to overall psychological capital.

\section{Method}

Through the prompts of management faculty and students of a large Midwestern university, 523 working 
adults volunteered for the survey. They were provided a link via electronic mail to an online secure server. Predictor variables and demographic background data were first collected (Time 1). A few weeks later, respondents were sent a link via electronic mail to complete a second portion of the survey comprising the outcome variables (Time 2). Separating the collection of prediction and criterion variables was done to minimize same source bias issues (see Podsakoff, MacKenzie, Lee, \& Podsakoff, 2003). As an incentive to complete the survey fully and accurately, respondents were promised and then provided at the end of the study an individualized report interpreting and explaining their survey results.

\section{Sample Demographics}

The majority $(59.7 \%)$ of the participants were male. Their age ranged from 20 to 73 years, with an average age of $43(S D=12.0)$. A large majority of them $(90 \%)$ were Caucasian. Educational level background included high school or less $(32.7 \%)$, associate's degrees (13.4\%), bachelor's degrees (33.3\%), and master's degrees or higher (19.7\%). Average tenure in the current organization was 12.1 years $(S D=10.6)$ with a range of less than 1 year to 40 years. Average tenure in the current position within the organization was 10.3 years $(S D=9.4)$ with a range of less than 1 year to 40 years. Positions within the organization included midlevel management $(28.7 \%)$, professional/administrative $(29.4 \%)$, executive leadership (11.3\%), clerical (7.5\%), customer service $(4.6 \%)$, and other $(18.5 \%)$. Industries represented included health care $(29.7 \%)$, manufacturing $(13.3 \%)$, services/retail $(9.2 \%)$, education $(6.7 \%)$, marketing $(7.2 \%)$, government $(2.7 \%)$, financial $(1.9 \%)$, and other $(29.3 \%)$. In other words, with the exception of being uncharacteristically ethnically homogeneous (i.e., largely White), the sample represents a broad cross section of typical working adults.

\section{Measures}

PsyCap was measured using the Psychological Capital Questionnaire (PCQ) developed by Luthans, Youssef, et al. (2007) that has undergone extensive validity analysis (Luthans, Avolio, et al., 2007). The shorter 12-item version of the PCQ was used in this study because of the measure's being collected three times per survey from each respondent in reference to one's health, relationships, and overall PsyCap. This PCQ-12 has been demonstrated to be reliable and valid in previous research (e.g., see Avey, Avolio, \& Luthans, 2011; Luthans, Avey, Smith, \& Li, 2008; Norman, Avolio, \& Luthans, 2010). Although the referent for the PCQ is work, the wording of the scales used in this study was slightly adapted when referring to health (Time 1), personal relationships (Time 1), and overall life (Time 2). Alpha reliabilities for these three adapted scales in this study were .89, .90 , and .92 , respectively.
The PCQ-12 contains three items to measure efficacy (originally adapted from Parker, 1998), four items to measure hope (originally adapted from C. R. Snyder et al., 1996), three to measure resilience (originally adapted from Wagnild \& Young, 1993), and two to measure optimism (originally adapted from Scheier \& Carver, 1985). Items were measured on a 6-point Likert-type scale ranging from strongly disagree to strongly agree. Representative items include the following: "I feel confident in representing my ideas concerning my personal relationships/health/life overall" (efficacy); "I always look on the bright side of things regarding my personal relationships/health/life overall" (optimism); "If I should find myself in a jam about my personal relationships/ health/life overall, I could think of many ways to get out of the jam" (hope); and "I usually take stressful things in stride with regard to my personal relationships/health/life overall" (resilience).

Relationship satisfaction was measured at both Time 1 and Time 2 with the 10-item scale developed by D. K. Snyder and Regts (1982). The alpha reliability coefficient of the scale was .88 at Time 1, and .91 at Time 2 . Items were measured on a 5-point Likert-type scale ranging from strongly disagree to strongly agree. Representative items include the following: "There are many things

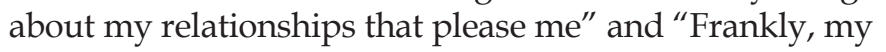
relationships have not been successful" (reverse-coded).

Relationship outcomes were measured at Time 2 by asking participants objective questions estimating the hours spent with family and friends over the course of an average week. Although only an estimate, the results were summed to represent an objective outcome of Relationship PsyCap.

Health satisfaction was measured at both Time 1 and Time 2 with the satisfaction subscale of the 12-item version of the SF (Short Form)-36 Health Survey using scoring methods described in Ware, Kosinski, Turner-Bowker, and Gandek (2002). This scoring scheme prevents calculation of an alpha reliability. Sample items include the following: "How much of the time during the past 4 weeks did you have a lot of energy?" and "During the past four weeks, to what extent has your physical health or emotional problems interfered with your normal social activities with family, friends, neighbors, or groups?"(reverse-scored).

The commonly used BMI and estimated cholesterol level were used to represent objective outcomes of Health PsyCap. Specifically, BMI was calculated from the respondents' reported height and weight information. Cholesterol was assessed through participants' rating on a 7-point scale ranging from far worse than average to far better than average. Since this was a well-being study that the participants were volunteering, these selfreports of objective health indicators were deemed to be known and accurately answered.

Work satisfaction was measured using the three-item job satisfaction scale from the Minnesota Satisfaction Questionnaire (Price \& Mueller, 1986). The alpha reliabil- 
ity coefficient was .86 . Items were measured on a 5-point Likert-type type scale ranging from strongly disagree to strongly agree. Items include the following: "All in all I am satisfied with my job," "In general, I don't like my job" (reverse-coded), and "In general, I like working here."

Overall well-being was measured with Berkman's (1971) widely recognized eight-item well-being scale. Items were measured on a 5-point Likert-type scale ranging from never to often for representative feelings including "on top of the world" and "bored" (reversecoded). The alpha reliability coefficient was .84 .

For control purposes, the Big Five personality traits of conscientiousness, agreeableness, and neuroticism were measured at Time 1. Specifically, to account for the topdown (i.e., dispositional) view of well-being, and to add rigor to the present findings, we assessed the unique contribution of state-like PsyCap beyond these widely recognized relatively stable Big Five personality traits. Donnellan, Oswald, Baird, and Lucas's (2006) Mini-IPIP (International Personality Item Pool) assessment of the Big Five was used. Representative items include the following: "sympathize with others' feelings" (agreeableness), "get chores done right away" (conscientiousness), and "have frequent mood swings" (neuroticism). The alpha reliability coefficients were .73 for agreeableness, .70 for conscientiousness, and .68 for neuroticism.

\section{Results}

Before the data were analyzed, they were screened and cleaned. Cases were excluded where the respondent did not complete both portions of the survey (there was an $83.5 \%$ response rate on the second portion). Furthermore, cases were removed where total survey completion time averaged less than 4 seconds per question. Based on previous research with similar data sets, we have found this to be roughly the threshold that indicates thoughtful versus thoughtless responding on this type of survey. Cases were also removed that contained any item with an "impossible" answer. This, for example, includes the two individuals who indicated working more than 168 hours per week. This data cleaning resulted in a final data set with 523 participants.

Given the new application to Health PsyCap and Relationship PsyCap, and the fact that they were measured using an adaptation of the established PCQ, a preliminary analysis was conducted to establish construct (convergent and discriminant) validity. Table 1 shows the extensive correlation matrix for the study and control variables. As indicated, PsyCap measures were positively correlated with agreeableness and conscientiousness and negatively correlated with neuroticism, reflecting convergence in the expected directions. However, the correlations ranged between .14 and .43, suggesting sufficient discriminant validity. Correlations between the various PsyCap domain measures ranged between .50 and .62. Although expected and still within acceptable norms, further analysis (described below) was conducted to establish discriminant validity of the various PsyCap domain measures.

Confirmatory factor analysis (CFA) was conducted for the two adapted PsyCap scales: Health PsyCap, $\chi^{2}(54)=445.02, p<.001$, comparative fit index $(\mathrm{CFI})=$ .96 , root mean square error of approximation (RMSEA) $=.118$, standardized root mean square residual (SRMR) $=.051$; and Relationship PsyCap, $\chi^{2}(54)=423.44, p<$ $.001, \mathrm{CFI}=.96$, RMSEA $=.118$, SRMR $=.051$. Furthermore, all the factor loadings were highly significant, and the majority of the factor loadings exceeded .5. As mentioned earlier, the alpha reliability coefficients were .89 for Health PsyCap and .90 for Relationship PsyCap. Whereas the chi-square values are high because of the large sample size, the fit statistics and reliability estimates were deemed adequate.

To establish further the construct validity of Health PsyCap and Relationship PsyCap, and their independence from PsyCap in other domains or an overarching PsyCap construct, an independent analysis was conducted in which two alternative models were contrasted, with the second model including a second-order factor. To avoid underidentification in CFAs with less than four first-order factors, Work PsyCap and Overall PsyCap were included in this analysis. The first model included Health, Relationship, Work, and Overall PsyCap, which were allowed to freely covary. In the second model, a second-order factor was added. A significant chi-square difference was found between the two models, $\Delta X(2)=17.27, p<.001$, indicating that they cannot be adequately accounted for by the second-order factor. This suggests that despite the relatively high correlations between the four types of PsyCap (health, relationship, work, and overall), there is enough discriminant validity across them to warrant treating them as independent constructs rather than just manifestations of an overarching PsyCap construct.

Next, the hypothesized relationships were tested through structural equation modeling. As recommended by Bollen (2000), a two-step process was undertaken. In the first step, CFA was conducted with the latent variables all allowed to correlate freely with each other. This CFA model suggests the proposed model represents the data.

The relationship life domain overall measurement model was then tested: $\chi^{2}(22)=475.087, p<.001$, CFI $=.959, \mathrm{RMSEA}=.047, \mathrm{SRMR}=.045$. This suggests the overall measurement model fit the data. Although the chi-square value is a bit high because of the large sample size, the fit statistics are acceptable per guidelines recommended by $\mathrm{Hu}$ and Bentler (1995). Figure 1 depicts the standardized relationships among the variables in the relationships domain model.

As shown in Figure 1, Relationship PsyCap at Time 1 is positively related to both relationship satisfaction and the objective outcome of hours spent with family and friends at Time 2 . Thus, Hypothesis 1 is fully supported. 
Table I. Correlation Matrix of Study Variables

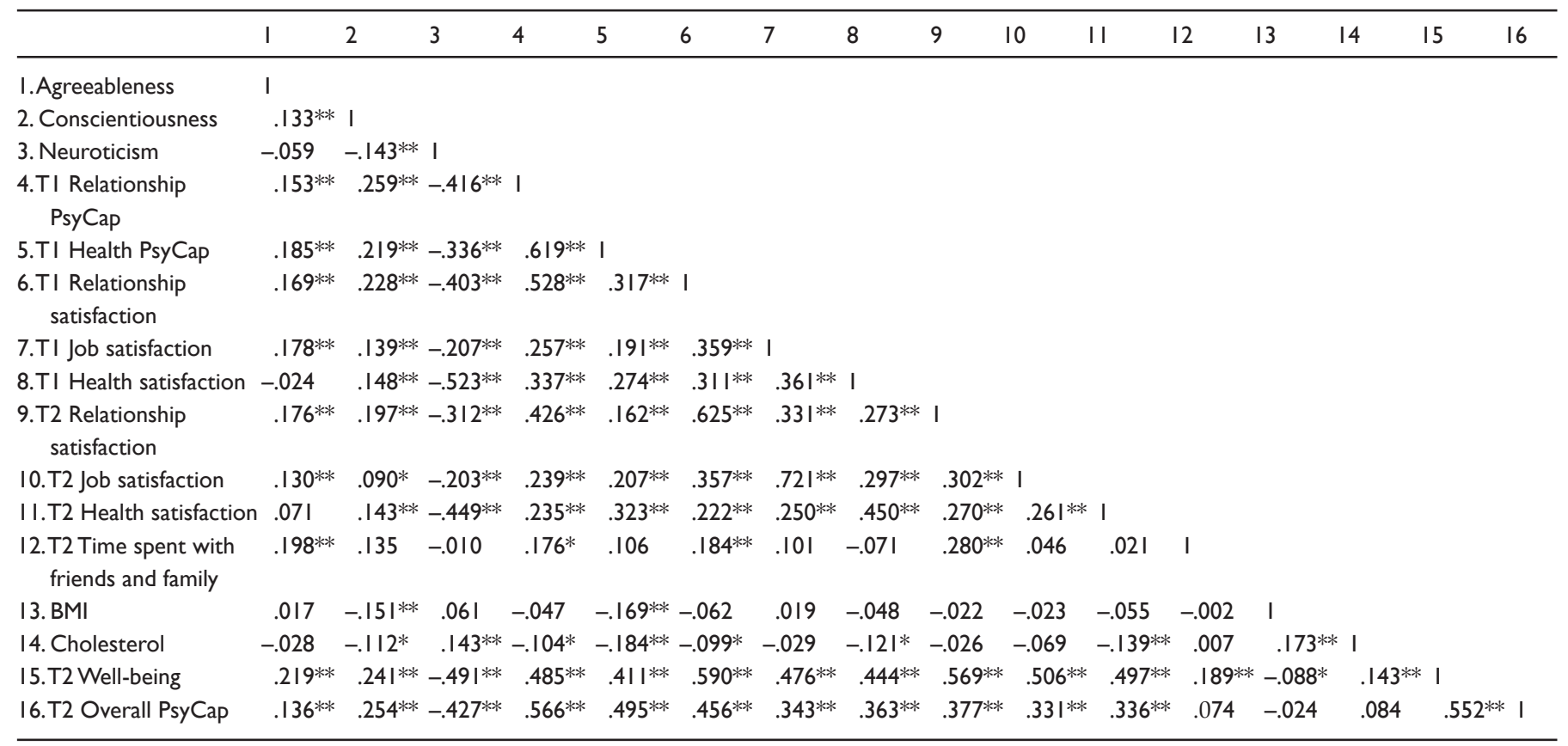

TI = Time I;T2 = Time 2; PsyCap = psychological capital; BMI = body mass index. $* p<.05$ (two-tailed). $* * p<.01$ (two-tailed).

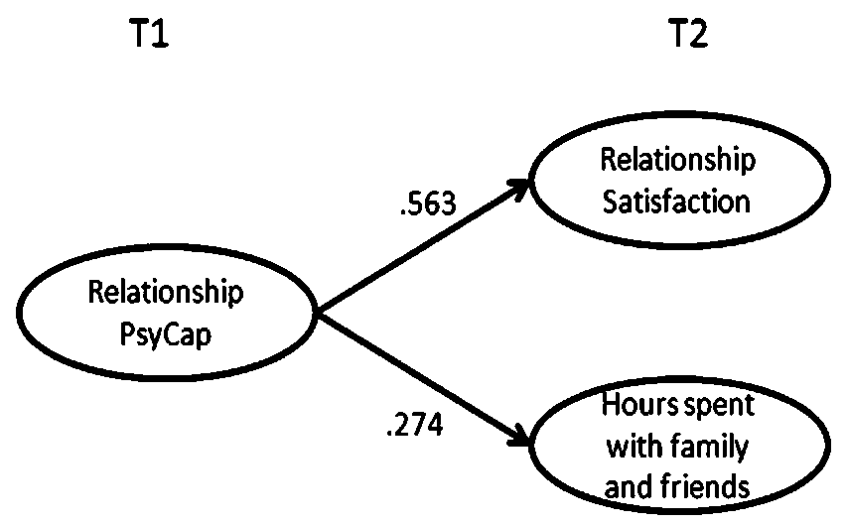

Figure I. Relationships domain model

Next, the health domain overall measurement model was tested: $\chi^{2}(81)=235.512, p<.001, \mathrm{CFI}=.949$, RMSEA $=.050, \mathrm{SRMR}=.043$. This suggests the overall measurement model fit the data. Again, although the chi-square value is a bit high because of the large sample size, the fit statistics are acceptable per guidelines recommended by $\mathrm{Hu}$ and Bentler (1995). Figure 2 depicts the standardized relationships between variables in the health domain model.

As illustrated in the Figure 2, Health PsyCap is positively related to health satisfaction and negatively related to the reported objective outcomes of BMI and cholesterol level, meaning a person higher in PsyCap possesses healthy BMI and cholesterol level. Thus, Hypothesis 2 is fully supported.

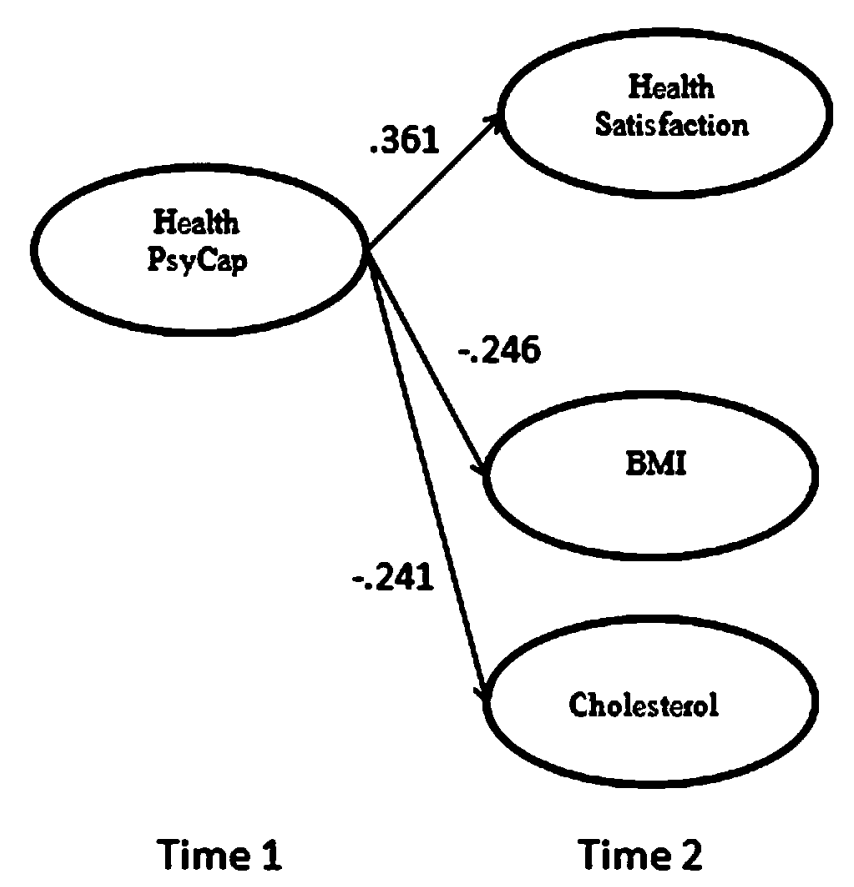

Figure 2. Health domain model

The overall measurement model for all three domains was then tested. $\chi^{2}(487)=98.298, p<.001$, CFI $=.950, \mathrm{RMSEA}=.043, \mathrm{SRMR}=.041$. This suggests the overall measurement model fit the data. Figure 3 depicts the standardized relationships among variables in the model. 


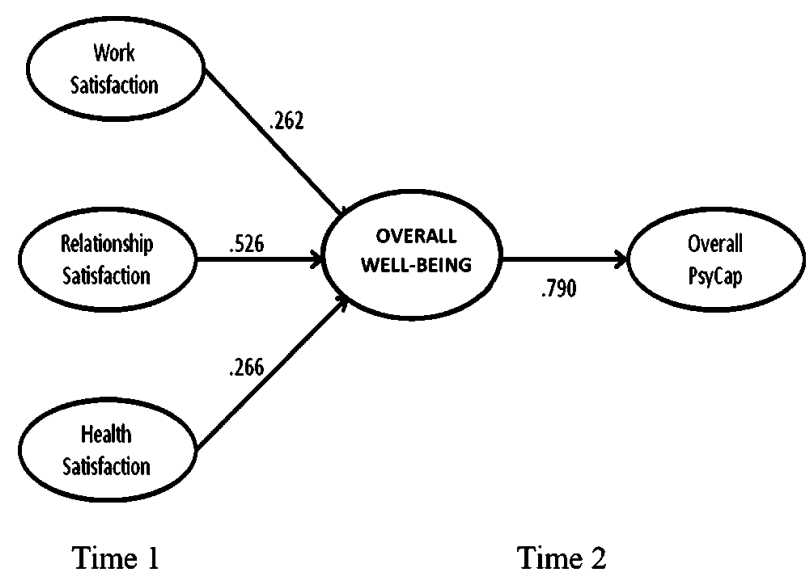

Figure 3. Domain satisfaction and overall well-being

As illustrated in the Figure 3, domain-specific satisfaction at Time 1 is positively related to overall wellbeing, which in turn is positively related to overall PsyCap, at Time 2. Thus, Hypotheses 3 and 4 are fully supported.

An additional series of hierarchical regression analyses were conducted to further test the hypothesized relationships and assess PsyCap's unique contributions, while accounting for the top-down (dispositional) and bottom-up (situational) views of well-being. Relationship PsyCap accounted for significant additional variance in relationship outcomes (time spent with friends and family) beyond personality traits $\left(R^{2}=.067, \Delta R^{2}=.032, p<.05\right)$. Furthermore, Relationship PsyCap accounted for significant additional variance in relationship satisfaction beyond both personality traits and relationship outcomes $\left(R^{2}=.246\right.$, $\left.\Delta R^{2}=.061, p<.001\right)$. Health PsyCap accounted for significant additional variance in health outcomes beyond personality traits $\left(R^{2}=.046, \Delta R^{2}=.019, p<.01\right.$, for BMI and $R^{2}=.048, \Delta R^{2}=.016, p<.01$, for cholesterol). Furthermore, Health PsyCap accounted for significant additional variance in health satisfaction beyond both personality traits and health outcomes $\left(R^{2}=.229, \Delta R^{2}=.024, p<\right.$ $.001)$. In most of the analyses, personality traits were not significant. Interestingly, participants' BMI and cholesterol level were not significant predictors of their health satisfaction.

Following conventions for testing mediated models (Baron \& Kenny, 1986), the full model was tested using a series of hierarchical regressions. Using overall wellbeing as the criterion, personality traits, Health PsyCap and Relationship PsyCap, and health and relationship objective outcomes were entered in Step 1, followed by health, relationship, and job satisfactions in Step 2 . Health, relationship, and job satisfactions were significant full mediators $(\beta s=.153, .321$, and $.201 ; p<.05$, .01 , and .001, respectively) and contributed significant unique variance to the model $\left(R^{2}=.556, \Delta R^{2}=.183, p<\right.$ .001). Health PsyCap was not significant in Step 1, but given its significant contribution to Health satisfaction in the previous analysis, its lack of significance here may be an artifact of its correlations with other variables.

Overall PsyCap was then used as the criterion. Personality traits, Health PsyCap and Relationship PsyCap and outcomes, and health, relationship, and job satisfaction were entered in Step 1, followed by overall well-being in Step 2. Overall well-being contributed significant unique variance to the model $\left(\beta=.221, R^{2}=.425, \Delta R^{2}=\right.$ $.022, p<.05$ ). However, there were also significant (but smaller) direct paths in Step 2 from job satisfaction $(\beta=$ $.241, p<.01)$ and Relationship PsyCap $(\beta=.235, p<.01)$, suggesting partial mediation. Furthermore, relationship and health satisfaction were not significant in Step 1 , but again, given their significant contribution as full mediators to overall well-being in the previous analysis, as well as their significance in the structural equation model, their lack of significance here may be an artifact of their correlations with other variables, which SEM accounts for. Overall, these results provide support for the hypothesized model.

\section{Discussion}

Over the years, organizational leadership has mainly been concerned with employee performance and satisfaction. However, prompted by the national (international) concern for the importance of building sustainable organizations (e.g., see Pfeffer, 2010), recent attention is being given to the well-being of today's employees. The same is true of the new focus on the role that positivity may play in leadership in general (e.g., see Cameron, 2008). As a way to help meet these challenges concerning both the role of positivity and wellbeing of employees facing the field of leadership, we have proposed the expansion of widely recognized positive PsyCap into the well-being domain through the new constructs of Relationship PsyCap and Health PsyCap.

Work PsyCap has been clearly demonstrated over the past few years to be related to employee attitudes, behaviors, and performance (for the meta-analysis, see Avey, Reichard, et al., 2011). Employees' work PsyCap has also been found to be related to measures of their well-being (Avey et al., 2010). In this study, we extended the investigation of the role that other life domains' level of PsyCap (i.e., Relationship PsyCap and Health PsyCap) are related to one's overall well-being. Specifically, we tested a temporal model in which well-being is conceptualized as a process that starts and ends with higher positivity. PsyCap appears to be a particularly relevant operationalization of positivity in relation to well-being in general, and human resource management and development in the workplace in particular. This relevancy of PsyCap is because of its balanced levels of stability and malleability, cognitive and affective content, and global 
and domain-specific applicabilities. Furthermore, support was found for a mutually reinforcing path of positivity, in which high domain-specific PsyCap (work, health, and relationships) leads to positive objective outcomes in these domains as well as increased domain satisfaction, which are related to higher overall well-being, which in turn relates to overall PsyCap.

Several practical implications for leaders to build the sustainability and well-being of their employees can be drawn from these findings. First, since PsyCap is a core construct that is open to human resource management and development (Luthans, Avey, et al., 2008; Luthans et al., 2010), effective leaders would seem wise to invest in the development of their employees' PsyCap. The return on investment in such PsyCap development interventions has been shown to be substantial (for specific utility analysis examples, see Luthans, Youssef, et al., 2007, pp. 217-226). The findings from this study expand the scope of these returns beyond the work domain to also include the other well-being essential dimensions of health and relationships.

The exponential increase in health care costs and the recognized contagion, spillover effects, and crossover effects from relationships at and beyond the workplace (Bakker, Westman, \& Van Emmerik, 2009) make a stronger case for PsyCap development. Although an increasing number of organizational leaders are experimenting or even implementing human resource development initiatives directly targeting changes in employees' unhealthy lifestyles or improvements in their relationships, they may be viewed as too invasive of employees' privacy and may have to be made optional because of legal considerations (Cascio \& Boudreau, 2008). On the other hand, PsyCap development interventions in the workplace may be a less intrusive, but evidence-based, effective approach to achieve not only work outcomes (Avey, Reichard, et al., 2011) but also the desired health and relationship outcomes, which in turn will enhance performance back on the job.

Second, work, health, relationships, and overall wellbeing seem to better fit a process or instrumental model, rather than a terminal value perspective. In other words, emphasis on the intentional pursuit of personally meaningful goals in a wide range of life domains is more likely to yield and sustain higher levels of domain satisfaction and overall well-being than just the active pursuit of happiness as an ideal goal (Schooler et al., 2003). Furthermore, this cognitive, agentic approach to wellbeing is supported by the study findings as leading to an upward spiral of positivity that has the potential of being self-reinforcing and self-sustaining.

Third, when considering positivity and happiness in general, and PsyCap in particular, leaders should give attention to multiple important life domains, including work, health, and relationships. For example, positivity has been shown to exhibit a threshold for flourishing or thriving (Fredrickson, 2009). To reach this "tipping point" of positivity over negativity identified by Fredrickson's (2009) work may necessitate positive, satisfying contributions from various life domains. Specifically, this seems required to overcome or compensate for negativity in these domains or others. In addition, higher positivity in a wide range of domains can promote the variety and novelty necessary to overcome acclimation to one's good fortunes (i.e., the dreaded hedonic "treadmill"). In addition, this wider scope can help facilitate the memory processes necessary for positive events to translate into higher levels of domain-specific appraisals of satisfaction and overall well-being (Kim-Prieto et al., 2005).

Among the strengths of this study's findings is the unique contribution to the literature in the form of a new conceptual model that relates domain-specific (i.e., relationships and health) PsyCap with objective outcomes and satisfaction, and in turn overall well-being and overall positivity (PsyCap). In addition, the model and the adapted measures of Health PsyCap and Relationship PsyCap extend for the first time the scope of PsyCap research beyond the occupational domain and contribute to its external validity. The large sample of employees from a broad cross section of industries and functions also provides for greater generalizability than smaller, single-firm samples. The time separation in collecting independent and dependent variables helps minimize common method bias issues in the relationship between predictor and outcome variables (Podsakoff et al., 2003). Controlling for personality traits and situational factors also accounts for both the traditionally used top-down and bottom-up well-being perspectives. This analysis highlights the unique contribution of the emerging intentional positivity and PsyCap to well-being beyond existing views and facilitates the integration of the conceptual framework with empirical findings of this study into the existing leadership and well-being body of knowledge.

Regarding limitations, conceptually, there is an ongoing debate regarding the relative contribution of immediate versus remembered events to well-being (Kahneman, 1999), as well as regarding the causal direction between happiness and various outcomes (Lyubomirsky, Sheldon, et al., 2005). As we conceptualized and tested in this study, adding PsyCap to the employee well-being challenge facing leaders may help resolve some of the contradictions. However, further research, more elaborate conceptual frameworks, and replication of empirical findings are obviously necessary. In addition, the debate continues regarding the extent of stability and malleability of well-being (Fujita \& Diener, 2005), including notions of an adaptational hedonic treadmill (Brickman \& Campbell, 1971) that renders the effect of any changes in wellbeing at best temporary. Although the variables in this study were measured over a short time period, longitudinal research in this area may need to span years, or even decades, and unique methods and measures may need to be developed to fit this type of research. 
In a related manner, a wide range of factors may moderate the relationships supported in this study between domain-specific PsyCap, domain satisfaction and objective outcomes, overall well-being, and overall PsyCap. For example, recent findings show that cognitive positivity-enhancing strategies may only be effective for individuals with positive dispositional traits but not for those predisposed to negativity (e.g., neurotics; see $\mathrm{Ng}$ \& Diener, 2009). Although neuroticism was controlled for in some of the analyses in this study, since PsyCap development and happiness-enhancing interventions rely on positive cognitive strategies, the validity of these interventions may be limited by some individual differences in personality characteristics. Similarly, cross-cultural and organizational culture norms may facilitate or hinder the contribution of PsyCap to various outcomes. In other words, PsyCap development interventions may vary in effectiveness because of context, and this needs to be tested in future research.

Methodologically, this study used a cross-sectional, self-report design that included neither random assignment nor experimental manipulations. Thus, despite the temporal separation in measuring the predictors and outcomes, causality cannot be concluded. It is possible, for example, that both PsyCap and satisfaction are predicted by a third construct, or that relational (or health) satisfaction leads to an increase in relationship-specific (or health-specific) PsyCap. Additionally, self-selection bias of the volunteer study participants could have influenced the results. Future research needs to leverage random sampling and longitudinal and experimental designs in order to provide for causal interpretability of the results.

In summary, the results of this study contribute to organizational leaders' better understanding of and additive empirical support for the notion that affect and cognitions in various life domains are inseparable and salient for their employees' overall well-being. The temporal process of well-being supported in this study and especially the integration of PsyCap as an operationalization of positivity as an antecedent and an outcome to the satisfaction appraisals of the three important life domains of work, relationships, and health represent unique contributions. The study findings can contribute to the leadership field by building the emerging, and now rapidly expanding, research stream and boundaries of the value of evidence-based positivity in general and PsyCap in particular.

Declaration - The authors received no financial support for and have no potential conflicts of interest with respect to the research, authorship, and/or publication of this article.

\section{References}

Avey, J. B., Avolio, B. J., \& Luthans, F. (2011). Experimentally analyzing the impact of leader positivity on follower positivity and performance. Leadership Quarterly, 22, 282-294.
Avey, J. B., Luthans, F., Smith, R. M., \& Palmer, N. F. (2010). Impact of positive psychological capital on employee wellbeing over time. Journal of Occupational Health Psychology, 15, 17-28.

Avey, J. B., Reichard, R., Luthans, F., \& Mhatre, K. (2011). Meta-analysis of the impact of positive psychological capital on employee attitudes, behaviors and performance. $\mathrm{Hu}$ man Resource Development Quarterly, 22, 127-152.

Bakker, A. B., Westman, M., \& Van Emmerik, I. J. H. (2009). Advances in crossover theory. Journal of Managerial Psychol$o g y, 24,206-219$.

Bandura, A. (1997). Self-efficacy: The exercise of control. New York, NY: Freeman.

Bandura, A. (2008). An agentic perspective on positive psychology. In S. J. Lopez (ed.), Positive psychology: Exploring the best in people (Vol. 1, pp. 167-196). Westport, CT: Greenwood.

Barnes, P. M., Bloom, B., \& Nahin, R. L. (2009). Complementary and alternative medicine use among adults and children: United States, 2007 (National Health Statistics Reports No. 12); http://www.cdc.gov/nchs/data/nhsr/nhsr012.pdf

Baron, R. M., \& Kenny, D. A. (1986). The moderator-mediator variable distinction in social psychological research: Conceptual, strategic and statistical considerations. Journal of Personality and Social Psychology, 51, 1173-1182.

Barsade, S. G. (2002). The ripple effect: Emotional contagion and its influence on group behavior. Administrative Science Quarterly, 47, 644-675.

Baumeister, R. F., Bratslavsky, E., Finkenauer, C., \& Vohs, K. D. (2001). Bad is stronger than good. Review of General Psychology, 5, 323-370

Berkman, P. L. (1971). Measurements of mental health in a general population survey. American Journal of Epidemiology, 41, 105-111.

Biswas-Diener, R., \& Diener, E. (2001). Making the best of a bad situation: Satisfaction in the slums of Calcutta. Social Indicators Research, 55, 329-352.

Biswas-Diener, R., Vitterso, J., \& Diener, E. (2005). Most people are pretty happy, but there is cultural variation: The Inughuit, the Amish, and the Maasai. Journal of Happiness Studies, 6, 205-226.

Bollen, K. A. (2000). Modeling strategies: In search of the Holy Grail. Structural Equation Modeling, 7, 74-81.

Brickman, P., \& Campbell, D. T. (1971). Hedonic relativism and planning the good society. In M. H. Appley (ed.), Adaptation level theory: A symposium (pp. 287-302). New York, NY: Academic Press.

Brief, A. P., Butcher, A. H., George, L. K., \& Link, K. (1993). Integrating bottom-up and top-down theories of subjective well-being: The case of health. Journal of Personality and Social Psychology, 64, 646-653.

Cameron, K. S. (2008). Positive leadership. San Francisco, CA: Berrett-Koehler.

Cameron, K. S., Dutton, J., \& Quinn, R. (eds.). (2003). Positive organizational scholarship. San Francisco, CA: Berrett- Koehler.

Cameron, K. S., \& Spritzer, G. M. (eds.). (2012). The Oxford handbook of positive organizational scholarship. New York, NY: Oxford University Press. 
Carver, C. S., \& Scheier, M. F. (1999). Themes and issues in the self-regulation of behavior. In R. S. Wyer Jr. (ed.), Advances in social cognition: Vol. 12. Perspectives on behavioral self-regulation (pp. 1-105). Mahwah, NJ: Erlbaum.

Carver, C. S., \& Scheier, M. (2002). Optimism. In C. R. Snyder \& S. Lopez (eds.), Handbook of positive psychology (pp. 231243). Oxford, England: Oxford University Press.

Cascio, W., \& Boudreau, J. (2008). Investing in people: Financial impact of human resource initiatives. Upper Saddle River, NJ: Pearson/FT Press.

Davidson, K., \& Prkachin, K. (1997). Optimism and unrealistic optimism have an interacting impact on health-promoting behavior and knowledge changes. Personality and Social Psychology Bulletin, 23, 617-625.

Diener, E., \& Biswas-Diener, R. (2008). Happiness: Unlocking the mysteries of psychological wealth. Malden, MA: Blackwell.

Diener, E., Lucas, R. E., \& Scollon, C. N. (2006). Beyond the hedonic treadmill: Revisions to the adaptation theory of wellbeing. American Psychologist, 61, 305-314.

Diener, E., Napa-Scollon, C. K., Oishi, S., Dzokoto, V., \& Suh, E. M. (2000). Positivity and the construction of life satisfaction judgments: Global happiness is not the sum of its parts. Journal of Happiness Studies, 1, 159-176.

Diener, E., Ng, W., \& Tov, W. (2009). Balance in life and declining marginal utility of diverse resources. Applied Research in Quality of Life, 3, 277-291.

Diener, E., Oishi, S., \& Lucas, R. E. (2009). Subjective well-being: The science of happiness and life satisfaction. In S. Lopez \& C. R. Snyder (eds.), Handbook of positive psychology (2nd ed., pp. 187-194). Oxford, England: Oxford University Press.

Diener, E., \& Seligman, M. E. P. (2002). Very happy people. Psychological Science, 13, 80-83.

Diener, E., Suh, E. M., Lucas, R. E., \& Smith, H. L. (1999). Subjective well-being: Three decades of progress. Psychological Bulletin, 125, 276-302.

Donnellan, M. B., Oswald, F. L., Baird, B. M., \& Lucas, R. E. (2006). The mini-IPIP scales: Tiny-yet-effective measures of the Big Five factors of personality. Psychological Assessment, 18, 192-203.

Dutton, J. E., \& Ragins, B. R. (eds.). (2007). Exploring positive relationships at work. Mahwah, NJ: Erlbaum.

Elliot, A. J., \& Sheldon, K. M. (1997). Avoidance achievement motivation: A personal goals analysis. Journal of Personality and Social Psychology, 73, 171-185.

Elliot, A. J., Sheldon, K. M., \& Church, M. A. (1997). Avoidance personal goals and subjective well-being. Personality and Social Psychology Bulletin, 23, 915-927.

Emmons, R. A., \& Diener, E. (1985). Factors predicting satisfaction judgments: A comparative examination. Social Indicators Research, 16, 157-168.

Fredrickson, B. L. (2001). The role of positive emotions in positive psychology: The broaden-and-build theory of positive emotions. American Psychologist, 56, 218-226.

Fredrickson, B. L. (2009). Positivity. New York, NY: Crown/ Random House.

Fredrickson, B. L., \& Losada, M. F. (2005). Positive affect and the complex dynamics of human flourishing. American Psychologist, 60, 678-686.
Fujita, F., \& Diener, E. (2005). Life satisfaction set-point: Stability and change. Journal of Personality and Social Psychology, $88,158-164$.

Gottman, J. M. (1994). What predicts divorce? The relationship between marital processes and marital outcomes. Hillsdale, NJ: Lawrence Erlbaum.

Heller, D., Watson, D., \& Ilies, R. (2004). The role of person versus situation in life satisfaction: A critical examination. Psychological Bulletin, 130, 574-600.

Holaday, M., \& McPhearson, R. (1997). Resilience and severe burns. Journal of Counseling and Development, 75, 346-356.

Holden, G. (1991). The relationship of self-efficacy appraisals to subsequent health-related outcomes: A meta-analysis. Social Work in Health Care, 16, 53-93.

Hu, L. T., \& Bentler, P. (1995). Evaluating model fit. In R. H. Hoyle (ed.), Structural equation modeling: Concepts, issues, and applications (pp. 76-99). London, England: Sage.

Judge, T. A., \& Ilies, R. (2004). Affect and job satisfaction: A study of their relationship at work and at home. Journal of Applied Psychology, 89, 4, 661-673.

Judge, T. A., \& Watanabe, S. (1993). Another look at the job satisfaction-life satisfaction relationship. Journal of Applied Psychology, 78, 939-948.

Kahneman, D. (1999). Objective happiness. In D. Kahneman, E. Diener, \& N. Schwarz (eds.), Well-being: Foundations of hedonic psychology (pp. 3-25). New York, NY: Russell Sage Foundation.

Kim-Prieto, C., Diener, E., Tamir, M., Scollon, C. N., \& Diener, M. (2005). Integrating the diverse definitions of happiness: A time-sequential framework of subjective well-being. Journal of Happiness Studies, 6, 261-300.

Kuoppala, J., Lamminpaa, A., Liira, J., \& Vainio, H. (2008). Leadership, job well-being and health effects: A systematic review and meta-analysis. Journal of Occupational and Environmental Medicine, 50, 904-915.

Levine, L. J. (1997). Reconstructing memory for emotions. Journal of Experimental Psychology: General, 126, 165-177.

Levine, L. J., Prohaska, V., Burgess, S. L., Rice, J. A., \& Laulere, T. M. (2001). Remembering past emotions: The role of current appraisals. Cognition E Emotion, 15, 393-417.

Lopez, S., \& Snyder, C. R. (eds.). (2009). Handbook of positive psychology (2nd ed.). Oxford, England: Oxford University Press.

Losada, M., \& Heaphy, E. (2004). The role of positivity and connectivity in the performance of business teams: A nonlinear dynamics model. American Behavioral Scientist, 47, 740-765.

Lucas, R. E., Clark, A. E., Georgellis, Y., \& Diener, E. (2003). Re-examining adaptation and the set point model of happiness: Reactions to changes in marital status. Journal of Personality and Social Psychology, 84, 527-539.

Lucas, R. E., Clark, A. E., Georgellis, Y., \& Diener, E. (2004). Unemployment alters the set point for life satisfaction. Psychological Science, 15, 8-13.

Luthans, F. (2002). The need for and meaning of positive organizational behavior. Journal of Organizational Behavior, 23, 695-706.

Luthans, F. (2012). Psychological capital: Implications for $\mathrm{HRD}$, retrospective analysis, and future directions. Human Resource Development Quarterly, 23, 1-8. 
Luthans, F., Avey, J. B., Avolio, B. J., \& Peterson, S. J. (2010). The development and resulting performance impact of positive psychological capital. Human Resource Development Quarterly, 21, 41-67.

Luthans, F., Avey, J. B., \& Patera, J. L. (2008). Experimental analysis of a web-based training intervention to develop positive psychological capital. Academy of Management Learning \& Education, 7, 209-221.

Luthans, F., Avey, J. B., Smith, R. C., \& Li, W. (2008). More evidence on the value of Chinese workers' psychological capital. International Journal of Human Resource Management, 19, 818-827.

Luthans, F., \& Avolio, B. J. (2003). Authentic leadership: A positive development approach. In K. S. Cameron, J. E. Dutton, \& R. E. Quinn (eds.), Positive organizational scholarship (pp. 241-258). San Francisco, CA: Berrett-Koehler.

Luthans, F., \& Avolio, B. J. (2009). The "point" of positive organizational behavior. Journal of Organizational Behavior, 30, 291-307.

Luthans, F., Avolio, B. J., Avey, J. B., \& Norman, S. M. (2007). Psychological capital: Measurement and relationship with performance and satisfaction. Personnel Psychology, 60, 541-572.

Luthans, F., \& Youssef, C. M. (2004). Human, social, and now positive psychological capital management. Organizational Dynamics, 33, 143-160.

Luthans, F., \& Youssef, C. M. (2007). Emerging positive organizational behavior. Journal of Management, 33, 321-349

Luthans, F., Youssef, C. M., \& Avolio, B. J. (2007). Psychological capital: Developing the human competitive edge. Oxford, England: Oxford University Press.

Lykken, D., \& Tellegen, A. (1996). Happiness is a stochastic phenomenon. Psychological Science, 7, 186-189.

Lyubomirsky, S. (2001). Why are some people happier than others? The role of cognitive and motivational processes in wellbeing. American Psychologist, 56, 239-249.

Lyubomirsky, S. (2007). The how of happiness: A new approach to getting the life you want. New York, NY: Penguin.

Lyubomirsky, S., King, L., \& Diener, E. (2005). The benefits of frequent positive affect: Does happiness lead to success? Psychological Bulletin, 131, 803-855

Lyubomirsky, S., Sheldon, K. M., \& Schkade, D. (2005). Pursuing happiness: The architecture of sustainable change. Review of General Psychology, 9, 111-131

Murray, S. L., Holmes, J. G., \& Griffin, D. W. (2003). Reflections on the self-fulfilling effects of positive illusions. Psychological Inquiry, 14, 289-295.

$\mathrm{Ng}, \mathrm{W} .$, \& Diener, E. (2009). Feeling bad? The "power" of positive thinking may not apply to everyone. Journal of Research in Personality, 43, 455-463.

Norman, S. M., Avolio, B. J., \& Luthans, F. (2010). The impact of positivity and transparency on trust in leadership and their perceived effectiveness. Leadership Quarterly, 21, 350-364.

Oishi, S. (2002). The experiencing and remembering of wellbeing: A cross-cultural analysis. Personality and Social Psychology Bulletin, 28, 1398-1406.

Oishi, S., Diener, E., \& Lucas, R. (2007). The optimum level of well-being: Can people be too happy? Perspectives on Psychological Science, 2, 346-360.
Okun, M. A., Stock, W. A., Haring, M. J., \& Witter, R. A. (1984). The social activity/subjective well-being relation: A quantitative synthesis. Research on Aging, 6, 45-65.

Parker, S. (1998). Enhancing role-breadth self efficacy: The roles of job enrichment and other organizational interventions. Journal of Applied Psychology, 83, 835-852.

Peterson, C., \& Seligman, M. (2004). Character strengths and virtues: A handbook and classification. New York, NY: Oxford University Press.

Peterson, S. J., \& Byron, K. (2008). Exploring the role of hope in job performance: Results from four studies. Journal of Organizational Behavior, 29, 785-803.

Peterson, S. J., Luthans, F., Avolio, B. J., Walumbwa, F., \& Zhang, Z. (2011). Psychological capital and employee performance: A latent growth modeling approach. Personnel Psychology, 64, 427-450.

Pfeffer, J. (2010). Building sustainable organizations: The human factor. Academy of Management Perspectives, 24, 34-45.

Podsakoff, P. M., MacKenzie, S. C., Lee, V., \& Podsakoff, N. P. (2003). Common method biases in behavioral research. Journal of Applied Psychology, 88, 879-903.

Price, J. L., \& Mueller, C. W. (1986). Handbook of organizational measurement. Marshfield, MA: Pitman.

Rusbult, C. E. (1980). Commitment and satisfaction in romantic associations: A test of the investment model. Journal of Personality and Social Psychology, 38, 172-186.

Ryan, R. M., \& Deci, E. L. (2001). On happiness and human potentials: A review of research on hedonic and eudaimonic well-being. Annual Review of Psychology, 52, 141-166.

Sandau-Beckler, P., Devall, E., de la \& Rosa, I. (2002). Strengthening family resilience: Prevention and treatment for highrisk substance-affected families. Journal of Individual Psychology, 58, 305-327.

Scheier, M. F., \& Carver, C. S. (1985). Optimism, coping and health: Assessment and implications of generalized outcome expectancies. Health Psychology, 4, 219-247.

Schooler, J. W., Ariely, D., \& Loewenstein, G. (2003). The pursuit and assessment of happiness may be self-defeating. In I. Brocas \& J. D. Carrillo (eds.), The psychology of economic decisions: Vol. 1. Rationality and well-being (pp. 41-70). New York: Oxford University Press.

Schwarzer, R., \& Jerusalem, M. (1995). Generalized self-efficacy scale. In J. Weinman, S. Wright, \& M. Johnson (eds.), Measures in health psychology: A user's portfolio (pp. 35-37). Windsor, England: NFER-Nelson.

Scioli, A., Chamberlin, C., Samor, C. M., LaPointe, A. B., Campbell, T. L., MacLeod, A. R., \& McLenon, J. A. (1997). A prospective study of hope, optimism, and health. Psychological Reports, 81, 723-733.

Seligman, M. E. P. (1998). Learned optimism. New York, NY: Pocket Books.

Seligman, M. E. P., \& Csikszentmihalyi, M. (2000). Positive psychology. American Psychologist, 55, 5-14.

Segrin, C. (2004). Concordance on negative emotion in close relationships: Emotional contagion or assortative mating? Journal of Social and Clinical Psychology, 23, 815-835.

Snyder, C. R., Ilardi, S., Michael, S. T., \& Cheavens, J. (2000). Hope theory: Updating a common process for psychological change. In C. R. Snyder \& R. E. Ingram (eds.), Hand- 
book of psychological change: Psychotherapy processes and practices for the 21st century (pp. 128-153). New York, NY: John Wiley.

Snyder, C. R., Sympson, S., Ybasco, F., Borders, T., Babyak, M., \& Higgins, R. (1996). Development and validation of the state hope scale. Journal of Personality and Social Psychology, 70, 321-335.

Snyder, D. K., \& Regts, J. M. (1982). Factor scales for assessing martial disharmony and disaffection. Journal of Consulting and Clinical Psychology, 50, 736-743.

Stajkovic, A. D., \& Luthans, F. (1998). Self-efficacy and workrelated performance: A meta-analysis. Psychological Bulletin, 124, 240-261.

Thomas, D. L., \& Diener, E. (1990). Memory accuracy in the recall of emotions. Journal of Personality and Social Psychology, 59, 291-297.

Wagnild, G. M., \& Young, H. M. (1993). Development and psychometric evaluation of the resiliency scale. Journal of Nursing Management, 1, 165-178.

Ware, J. E., Kosinski, M., Turner-Bowker, D. M., \& Gandek, B. (2002). How to score: Version 2 of the SF-12 Health Survey (with a supplement documenting Version 1). Lincoln, RI: Quality Metric.

Wirtz, D., J., Kruger, C. N., Scollon, E., \& Diener, E. (2004). What to do on spring break? Predicting future choice from online versus recalled affect, Psychological Science, 14, 520-524.

Youssef, C. M., \& Luthans, F. (2007). Positive organizational behavior in the workplace: The impact of hope, optimism, and resilience. Journal of Management, 33, 774-800.

Youssef, C. M., \& Luthans, F. (2012). Positive global leadership. Journal of World Business, 47, 539-547.

\section{The Authors}

Fred Luthans is University and Holmes Distinguished Professor of Management at the University of Nebraska. A former President of the Academy of Management and editor of three journals, his research has been devoted to psychological capital since he formulated the construct over a decade ago.

Carolyn M. Youssef is the Redding Endowed Chair in the College of Business at Bellevue University and a core faculty member in the PhD in Human Capital Management program. She received her $\mathrm{PhD}$ from the University of $\mathrm{Ne}-$ braska. Besides coauthoring Psychological Capital (Oxford, 2007) with Fred Luthans and Bruce Avolio, her research on psychological capital has been published in numerous journals.

David S. Sweetman is the Director of Information Technology at the University of Michigan, College of Literature, Science, and the Arts. He earned his PhD in organizational behavior at the University of Nebraska and MBA from the Ross School of Business. His work focuses on strategic change, creativity and innovation, and strength-based leadership.

Peter D. Harms is an Assistant Professor of Management at the University of Nebraska. He received his $\mathrm{PhD}$ from the University of Illinois. His research focuses on the assessment and development of personality, leadership, and psychological well-being. He is currently working with the U.S. Army to evaluate and improve the Comprehensive Soldier and Family Fitness program, a resilience- development initiative. 